\title{
Stress and Coping to Nursing College Students
}

\author{
Eun Ju Kim \\ Dept. of Nursing, Hanseo University, 46, Hanseo 1-ro, Haemi-Myun, Seosan-Si, \\ Chungcheognam-do, Republic of Korea \\ eunjkim@hanseo.ac.kr
}

\begin{abstract}
The purpose of this study was to investigate the relationship between stress levels and the coping style of nursing college students. And to find and provide effective stress-coping strategies. Data were collected from 257 nursing college students and analyzed by descriptive statistics, t-test, ANOVA, and Pearson's Correlation Coefficient. Nursing college students were more stressed at the lower economic level, pocket money level, and major satisfaction. The coping strategies of nursing college students were mainly related to avoidance centering stress coping style and were not related to coping style through problem-solving and social support seeking. In conclusion, nursing college students lack coping behavior to find their willingness to solve problems themselves and their coping resources in the process of coping with stress and mainly related to passive coping methods to avoid stressful situations. Therefore, it is necessary to develop a stress-coping intervention program that can develop methods and abilities to relieve stress and mediate it.
\end{abstract}

Keywords: Stress, Coping, Nursing, College, Students

\section{Introduction}

College students generally have a relatively low mortality rate or morbidity rate and are a good group to maintain better health conditions through continuous management of erroneous lifestyles or stress [1]. However, it is also an unstable group that is exposed to various stressful environments such as new college culture and human relations and needs to study, the uncertainty of the future, and independence from parents [2].

Stress is a tense state that manifests itself as an individual's physical or mental behavior response to a stressor; it is also a cause of mental illness [3]. Gradually, as the intensity of stress perceived by college students increases, serious problems such as school maladjustment, interpersonal problems, and anxiety about career and employment may be accompanied. The need for management and intervention in the stress they are experiencing has been raised [4].

Nursing college students may be more stressed due to the specificity of the nursing department. Unlike other college students, there are two types of stress sources simultaneously working on heavy learning and clinical practice [2].

If these stresses persist and are not effectively managed, they can experience various physical health problems and psychological difficulties such as anxiety, tension, frustration,

Article history:

Received (January 11, 2019), Review Result (February 11, 2019), Accepted (March 15, 2019) 
and depression [5]. Ineffective coping and inadequate management of stress can lead to academic abandonment [6]. Therefore, it is necessary to precisely assess, manage, and resolve the stress level as well as stress factors of nursing college students in the education field

Until recently, nursing college students' stress-related studies have mainly dealt with the stress caused by the clinical practice of nursing college students [7][8], and other research on academic stress and job stress [9][10]. However, there are few kinds of research related to college life stress and coping styles of nursing college students.

In this study, we try to understand the level of stress experienced by nursing college students and analyze the relationship with coping strategies. This study attempted to find out how to cope with the effective stress of nursing college students.

\section{Materials and methods}

\subsection{Participants}

A questionnaire survey considering ethical aspects was distributed to 260 nursing college students selected from three universities. Of the 260 questionnaires, 257 were selected for final analysis. 3 questionnaires with some incomplete responses were excluded.

\subsection{Measurements}

\subsubsection{Questionnaire on stress}

The stress instrument is the life stress scale that corrects and supplements the college student stress scale of Kyum and Kyo [11]. This tool is composed of 8 areas and 50 questions, with each response, ranked on a 5-point Likert scale. Higher scores indicate greater stress. It covers 4 areas of interpersonal stress (opposite-sex friends, same-sex friends, family, professors) and four problem stress areas (academic, economic, future, value) in college students. Cronbach's $\alpha$ value was .85.

\subsubsection{Questionnaire on coping}

The Korean version of the Stress Coping Strategic Instrument (K-CSI) tool developed by Shin [12] was used to measure coping strategies for stress. The total of 18 questions consists of three areas (social support seeking, problem-solving, and avoidance centering). Each item has a 3-point scale, which means that the higher the score, the higher the degree of using the coping strategy Cronbach's $\alpha$ value was .76.

\subsection{Data collection and analyses}

A total of 260 nursing college students were individually met by trained research interviewers. The interviewers explained the mobile survey and asked participants to complete the questions using their own mobile devices. All participants provided informed written consent before participating and were assured that the information would never be used for any other purpose. Data were analyzed using the SPSS/WIN 22.0 program. ANOVA, t-test, and Pearson's Correlation Coefficient were used. 


\section{Results}

\subsection{General characteristics}

Of the 257 respondents, $229(89.1 \%)$ were female, $154(59.9 \%)$ were $20 \sim 21$ years of age and $121(47.1 \%)$ were sophomore students. $182(70.8 \%)$ respondents were medium economic level.

\subsection{Differences in stress level according to general characteristics}

In nursing students, the less interpersonal stress with the professor, the higher their satisfaction with the major. The stress of interpersonal relationships with same-sex friends, opposite-sex friends, and family differed according to pocket money level [Table 1].

Table 1. Differences in interpersonal stress level according to general characteristics

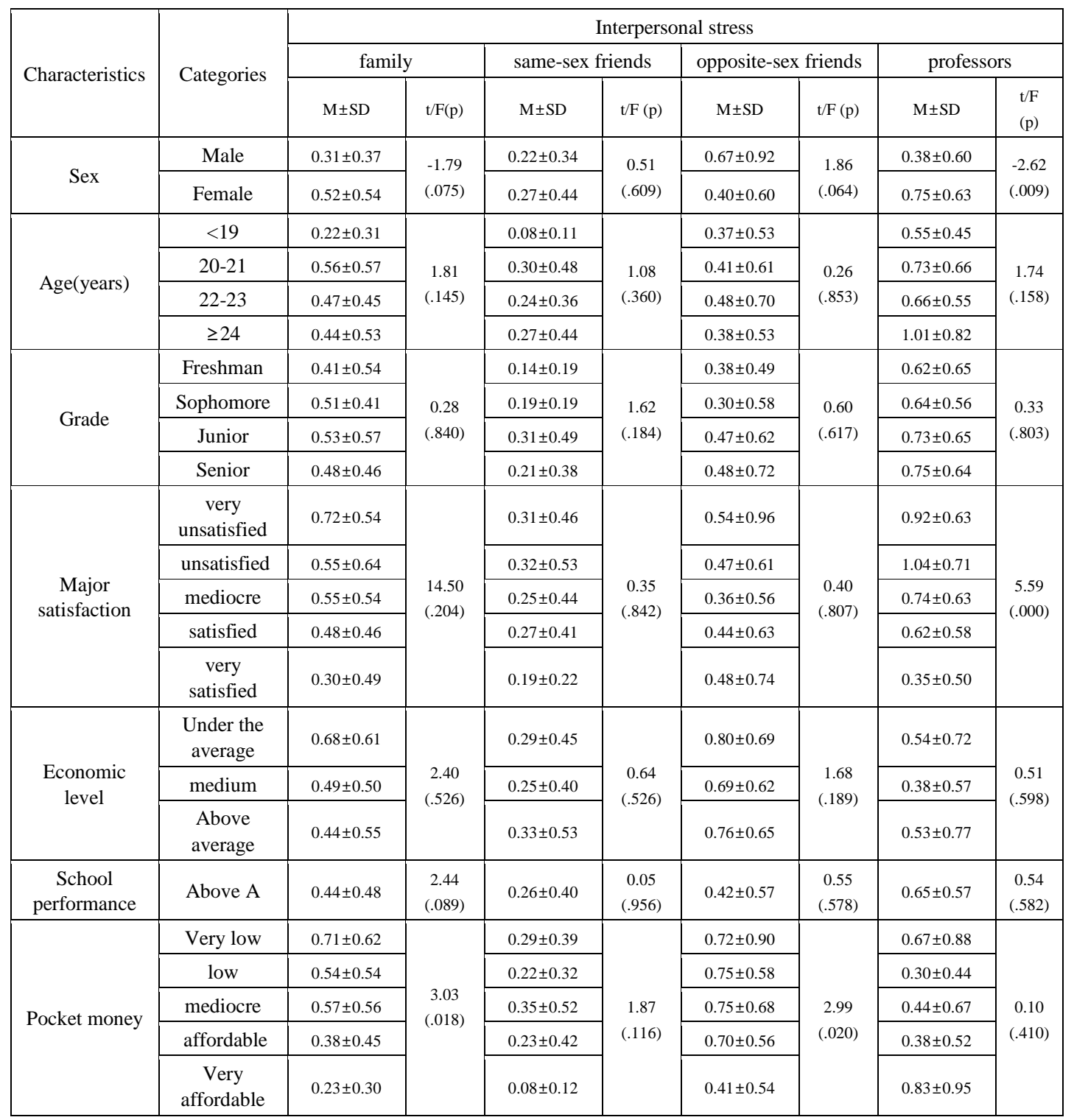




\begin{tabular}{|c|c|c|c|c|c|c|c|c|c|}
\hline \multirow{3}{*}{$\begin{array}{c}\text { School } \\
\text { performance }\end{array}$} & Above A & $0.44 \pm 0.48$ & \multirow{3}{*}{$\begin{array}{c}2.44 \\
(.089)\end{array}$} & $0.26 \pm 0.40$ & \multirow{3}{*}{$\begin{array}{l}0.05 \\
(.956)\end{array}$} & $0.42 \pm 0.57$ & \multirow{3}{*}{$\begin{array}{c}0.55 \\
(.578)\end{array}$} & $0.65 \pm 0.57$ & \multirow{3}{*}{$\begin{array}{c}0.54 \\
(.582)\end{array}$} \\
\hline & B & $0.49 \pm 0.52$ & & $0.27 \pm 0.43$ & & $0.40 \pm 0.62$ & & $0.74 \pm 0.61$ & \\
\hline & Under C & $0.63 \pm 0.60$ & & $0.28 \pm 0.49$ & & $0.50 \pm 0.76$ & & $0.76 \pm 0.76$ & \\
\hline
\end{tabular}

Table 2. Differences in problem stress level according to general characteristics

\begin{tabular}{|c|c|c|c|c|c|c|c|c|c|c|c|}
\hline \multirow{3}{*}{$\begin{array}{l}\text { Char } \\
\text { acteri } \\
\text { stics }\end{array}$} & \multirow{3}{*}{$\begin{array}{l}\text { Categori } \\
\text { es }\end{array}$} & \multicolumn{8}{|c|}{ Problem stress } & \multirow{2}{*}{\multicolumn{2}{|c|}{ Total stress }} \\
\hline & & \multicolumn{2}{|c|}{ Value } & \multicolumn{2}{|c|}{ Economic } & \multicolumn{2}{|c|}{ Academic } & \multicolumn{2}{|c|}{ Future } & & \\
\hline & & $\mathrm{M} \pm \mathrm{SD}$ & $t / F(p)$ & $\mathrm{M} \pm \mathrm{SD}$ & $\begin{array}{l}\mathrm{t} / \mathrm{F} \\
(\mathrm{p})\end{array}$ & $\mathrm{M} \pm \mathrm{SD}$ & $\begin{array}{c}\mathrm{t} / \mathrm{F}(\mathrm{p} \\
)\end{array}$ & $\mathrm{M} \pm \mathrm{SD}$ & $\begin{array}{c}\mathrm{t} / \mathrm{F}(\mathrm{p} \\
)\end{array}$ & $\mathrm{M} \pm \mathrm{SD}$ & $\begin{array}{l}\mathrm{t} / \mathrm{F} \\
(\mathrm{p})\end{array}$ \\
\hline \multirow{2}{*}{ Sex } & Male & $0.70 \pm 0.53$ & \multirow{2}{*}{$\begin{array}{l}-1.28 \\
(.201)\end{array}$} & $0.46 \pm 0.46$ & \multirow{2}{*}{$\begin{array}{c}-1.08 \\
(.283 \\
)\end{array}$} & $1.06 \pm 0.51$ & \multirow{2}{*}{$\begin{array}{c}-2.81 \\
(.005 \\
)\end{array}$} & $1.10 \pm 0.58$ & \multirow{2}{*}{$\begin{array}{c}-1.93 \\
(.055 \\
)\end{array}$} & $0.58 \pm 0.33$ & \multirow{2}{*}{$\begin{array}{c}-1.72 \\
(.087 \\
)\end{array}$} \\
\hline & Female & $0.87 \pm 0.60$ & & $0.59 \pm 0.55$ & & $1.37 \pm 0.49$ & & $1.35 \pm 0.59$ & & $0.73 \pm 0.38$ & \\
\hline \multirow{4}{*}{$\begin{array}{c}\text { Age( } \\
\text { years } \\
\text { ) }\end{array}$} & $<19$ & $0.85 \pm 0.64$ & \multirow{4}{*}{$\begin{array}{c}0.72 \\
(.539)\end{array}$} & $0.26 \pm 0.35$ & \multirow{4}{*}{$\begin{array}{c}2.27 \\
(.081 \\
)\end{array}$} & $1.41 \pm 0.31$ & \multirow{4}{*}{$\begin{array}{c}0.30 \\
(.823 \\
)\end{array}$} & $1.06 \pm 0.76$ & \multirow{4}{*}{$\begin{array}{c}2.08 \\
(.104 \\
)\end{array}$} & $0.56 \pm 0.25$ & \multirow{4}{*}{$\begin{array}{c}1.07 \\
(.363 \\
)\end{array}$} \\
\hline & $20-21$ & $0.88 \pm 0.60$ & & $0.63 \pm 0.56$ & & $1.36 \pm 0.46$ & & $1.38 \pm 0.54$ & & $0.74 \pm 0.40$ & \\
\hline & $22-23$ & $0.84 \pm 0.56$ & & $0.56 \pm 0.53$ & & $1.30 \pm 0.56$ & & $1.31 \pm 0.64$ & & $0.70 \pm 0.34$ & \\
\hline & $\geq 24$ & $0.66 \pm 0.60$ & & $0.42 \pm 0.47$ & & $1.31 \pm 0.59$ & & $1.11 \pm 0.54$ & & $0.66 \pm 0.41$ & \\
\hline \multirow{3}{*}{$\begin{array}{c}\text { Grad } \\
\mathrm{e}\end{array}$} & $\begin{array}{c}\text { Freshma } \\
n\end{array}$ & $0.82 \pm 0.59$ & \multirow{3}{*}{$\begin{array}{l}1.17 \\
(.323)\end{array}$} & $0.33 \pm 0.37$ & \multirow{3}{*}{$\begin{array}{c}2.90 \\
(.036 \\
)\end{array}$} & $1.39 \pm 0.35$ & \multirow{3}{*}{$\begin{array}{c}0.82 \\
(.483 \\
)\end{array}$} & $1.11 \pm 0.70$ & \multirow{3}{*}{$\begin{array}{c}2.91 \\
(.035 \\
)\end{array}$} & $0.62 \pm 0.29$ & \multirow{3}{*}{$\begin{array}{c}1.05 \\
(.370 \\
)\end{array}$} \\
\hline & $\begin{array}{l}\text { Sophom } \\
\text { ore } \\
\text { Junior }\end{array}$ & $\begin{array}{l}0.95 \pm 0.49 \\
0.88 \pm 0.61\end{array}$ & & $\begin{array}{l}0.67 \pm 0.48 \\
0.62 \pm 0.57\end{array}$ & & $\begin{array}{l}1.31 \pm 0.48 \\
1.37 \pm 0.50\end{array}$ & & $\begin{array}{l}1.31 \pm 0.45 \\
1.40 \pm 0.60\end{array}$ & & $\begin{array}{l}0.70 \pm 0.25 \\
0.74 \pm 0.40\end{array}$ & \\
\hline & Senior & $0.73 \pm 0.60$ & & $0.44 \pm 0.51$ & & $1.26 \pm 0.53$ & & $1.17 \pm 0.59$ & & $0.66 \pm 0.36$ & \\
\hline \multirow{4}{*}{$\begin{array}{l}\text { Majo } \\
\text { r } \\
\text { satisf } \\
\text { actio } \\
\text { n }\end{array}$} & $\begin{array}{c}\text { very } \\
\text { unsatisfi } \\
\text { ed }\end{array}$ & $0.85 \pm 0.55$ & \multirow{4}{*}{$\begin{array}{l}1.26 \\
(.286)\end{array}$} & $0.61 \pm 0.53$ & \multirow{4}{*}{$\begin{array}{c}1.40 \\
(.234 \\
)\end{array}$} & $1.76 \pm 0.47$ & \multirow{4}{*}{$\begin{array}{c}2.49 \\
(.044 \\
)\end{array}$} & $1.56 \pm 0.52$ & \multirow{4}{*}{$\begin{array}{c}2.34 \\
(.055 \\
)\end{array}$} & $0.85 \pm 0.31$ & \\
\hline & $\begin{array}{l}\text { unsatisfi } \\
\text { ed } \\
\text { mediocr } \\
\text { e }\end{array}$ & $\begin{array}{l}1.00 \pm 0.59 \\
0.88 \pm 0.60\end{array}$ & & $0.62 \pm 0.58$ & & $1.38 \pm 0.47$ & & $1.40 \pm 0.66$ & & $\begin{array}{l}0.82 \pm 0.44 \\
0.72 \pm 0.40\end{array}$ & $\begin{array}{c}2.09 \\
(.083 \\
)\end{array}$ \\
\hline & satisfied & $0.80 \pm 0.60$ & & $0.50 \pm 0.48$ & & $1.28 \pm 0.48$ & & $1.28 \pm 0.58$ & & $0.67 \pm 0.34$ & \\
\hline & $\begin{array}{c}\text { very } \\
\text { satisfied }\end{array}$ & $0.70 \pm 0.52$ & & $0.48 \pm 0.57$ & & $1.27 \pm 0.40$ & & $1.03 \pm 0.50$ & & $0.59 \pm 0.26$ & \\
\hline $\begin{array}{l}\text { Econ } \\
\text { omic } \\
\text { level }\end{array}$ & $\begin{array}{l}\text { Under } \\
\text { the } \\
\text { average } \\
\text { medium }\end{array}$ & $\begin{array}{l}0.99 \pm 0.66 \\
0.81 \pm 0.55\end{array}$ & $\begin{array}{c}1.51 \\
(.223)\end{array}$ & $0.54 \pm 0.49$ & $\begin{array}{l}11.83 \\
. .000 \\
)\end{array}$ & $1.31 \pm 0.51$ & $\begin{array}{c}1.89 \\
(.154 \\
)\end{array}$ & $1.33 \pm 0.58$ & $\begin{array}{c}0.23 \\
. .799 \\
)\end{array}$ & $\begin{array}{l}0.86 \pm 0.42 \\
0.68 \pm 0.35\end{array}$ & $\begin{array}{l}3.50 \\
(.032 \\
)\end{array}$ \\
\hline & $\begin{array}{l}\text { Above } \\
\text { average }\end{array}$ & $0.90 \pm 0.69$ & & $0.55 \pm 0.41$ & & $1.33 \pm 0.46$ & & $1.27 \pm 0.55$ & & $0.71 \pm 0.42$ & \\
\hline & $\begin{array}{l}\text { Very } \\
\text { low }\end{array}$ & $0.85 \pm 0.69$ & & $0.83 \pm 0.63$ & & $1.37 \pm 0.47$ & & $1.25 \pm 0.57$ & & $0.79 \pm 0.44$ & \\
\hline & low & $0.87 \pm 0.56$ & & $0.69 \pm 0.55$ & & $1.42 \pm 0.54$ & & $1.37 \pm 0.59$ & & $0.74 \pm 0.32$ & \\
\hline pock & $\begin{array}{c}\text { mediocr } \\
\mathrm{e}\end{array}$ & $0.95 \pm 0.58$ & & $0.62 \pm 0.52$ & & $1.41 \pm 0.47$ & 2.91 & $1.39 \pm 0.62$ & 1.75 & $0.77 \pm 0.41$ & \\
\hline $\begin{array}{c}\text { mone } \\
y\end{array}$ & $\begin{array}{c}\text { affordab } \\
\text { le }\end{array}$ & $0.71 \pm 0.63$ & $(.103)$ & $0.42 \pm 0.51$ & $\begin{array}{c}(.000 \\
)\end{array}$ & $1.16 \pm 0.46$ & ) & $1.27 \pm 0.52$ & ) & $0.62 \pm 0.35$ & $\begin{array}{c}.032 \\
)\end{array}$ \\
\hline & $\begin{array}{c}\text { Very } \\
\text { affordab } \\
\text { le }\end{array}$ & $0.65 \pm 0.43$ & & $0.07 \pm 0.11$ & & $1.28 \pm 0.52$ & & $1.00 \pm 0.66$ & & $0.52 \pm 0.26$ & \\
\hline $\begin{array}{c}\text { Scho } \\
\text { ol }\end{array}$ & $\begin{array}{c}\text { Above } \\
\text { A }\end{array}$ & $0.84 \pm 0.52$ & $\begin{array}{l}0.18 \\
(.839)\end{array}$ & $0.48 \pm 0.50$ & $\begin{array}{l}1.72 \\
(.182\end{array}$ & $1.20 \pm 0.44$ & $\begin{array}{l}5.64 \\
(.004\end{array}$ & $1.18 \pm 0.56$ & $\begin{array}{l}3.64 \\
.028\end{array}$ & $0.65 \pm 0.32$ & $\begin{array}{l}2.06 \\
(.130\end{array}$ \\
\hline
\end{tabular}




\begin{tabular}{|c|c|c|c|c|c|c|c|c|c|c|}
\hline \multirow{2}{*}{$\begin{array}{c}\text { perfo } \\
\text { rman } \\
\text { ce }\end{array}$} & B & $0.84 \pm 0.59$ & $0.60 \pm 0.56$ & \multirow[t]{2}{*}{ ) } & $1.36 \pm 0.52$ & \multirow[t]{2}{*}{ ) } & $1.42 \pm 0.54$ & \multirow[t]{2}{*}{ ) } & $0.72 \pm 0.36$ & \multirow[t]{2}{*}{ ) } \\
\hline & Under C & $0.89 \pm 0.68$ & $0.58 \pm 0.55$ & & $1.48 \pm 0.49$ & & $1.32 \pm 0.70$ & & $0.78 \pm 0.45$ & \\
\hline
\end{tabular}

The economic stresses varied depending on grade, economic level, and pocket money. The school-related stresses were different according to major satisfaction, school performance, and pocket money. Stress on the future varied depending on the grade and school performance [Table 2].

\subsection{Correlation among stress, coping, general characteristics}

The stress level of nursing college students correlated with avoidance centering stress coping style. The level of stress was high when the major satisfaction level, economic level, and pocket money level were low.

The stresses of the eight areas of stress were also correlated with avoidance-centering coping strategies, including economic, friends, professors, value, family, academic, and future problems. Also, stress related to same-sex friendships correlated with social support-seeking and avoidance-centering coping styles.

Table 3. Correlation among stress, coping, general characteristics

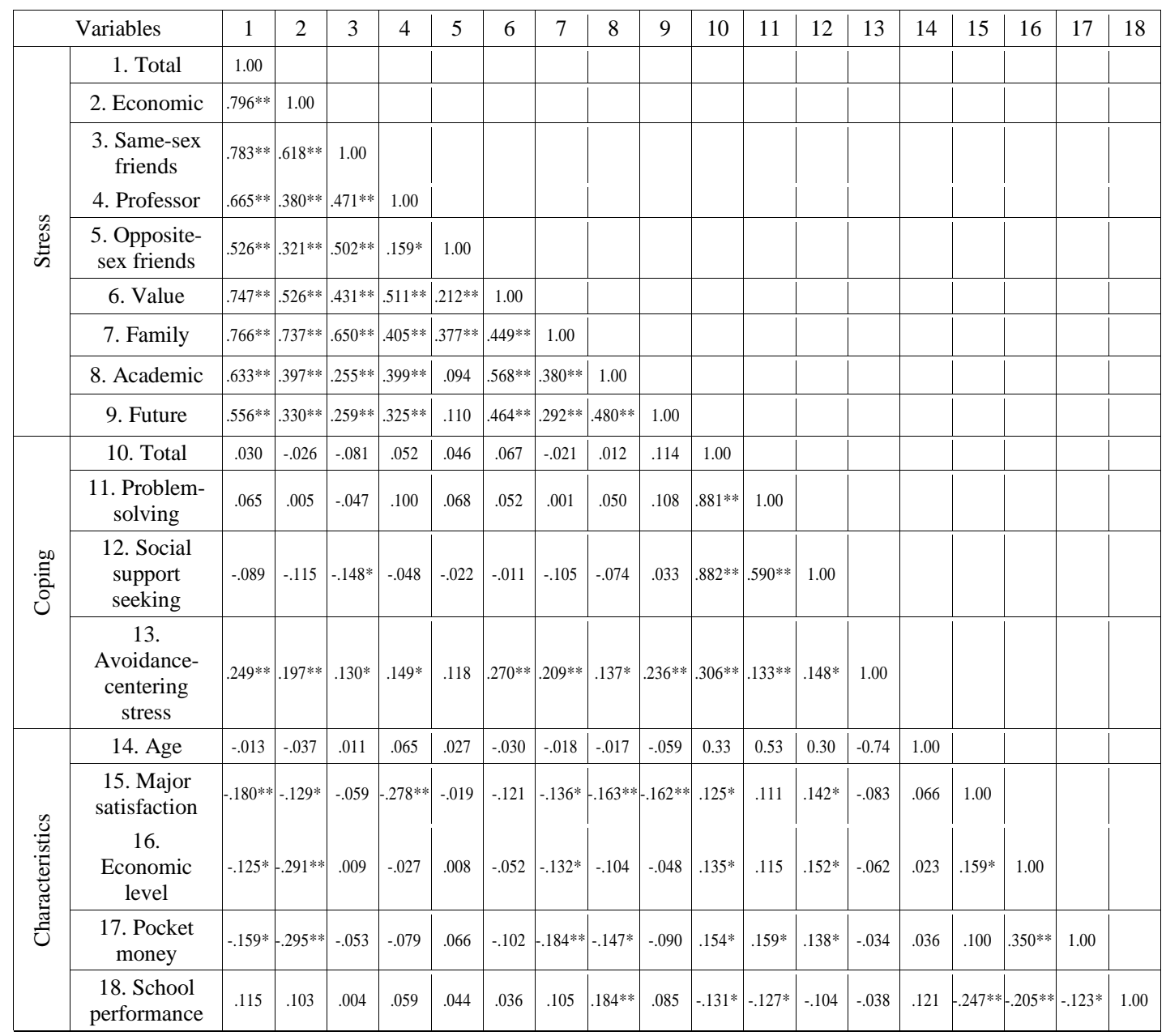


Stress coping level was higher when the major satisfaction level, economic level, and pocket money level were high. However, the higher the school grades, the lower the stress coping level. [Table 3] shows that the problem-solving methods and the social supportseeking coping methods of the sub-domain coping methods are correlated with pocket money [Table 3].

\section{Conclusion}

The purpose of this study was to identify the level of stress experienced by nursing students and to understand the relationship with coping style. This was done to find and provide effective stress coping.

The nursing students were more stressed when their economic level, pocket money level, and major satisfaction were lower.

Coping with stress was mainly related to an avoidance-focused stress coping style. And was not related to coping style through problem-solving and social support seeking. In addition, among the stresses of the eight sub-area, the seven stress areas (economics, friends, professors, values, family, academic studies, and future problems) except stressful heterosexual interpersonal stress, were mainly related to avoidance-focused stress coping strategies.

In conclusion, the nursing students showed that economic level, pocket money level, and major satisfaction were correlated with stress level. In addition, the stress coping method was mainly used to avoid stress. In other words, nursing students had difficulty in finding the active will to solve problems themselves and the coping resources to cope with themselves in the stress situation such as encountering difficulties in the adaptation process, and mainly related to passive coping methods to avoid the stressful situation.

Therefore, nursing college students need to use more effective coping rather than unconditionally avoiding stressful situations. For this, there is a need to develop and intervene stress coping nursing intervention programs that can develop methods and abilities to relieve stress.

\section{References}

[1] S. Y. Lee, Wuertz C., Rogers R., and Chen Y. P., "Stress and sleep disturbances in female college students," American Journal of Health Behavior, vol.37, no.6, pp.851-858, (2013)

[2] J. Y. Shin, "The mediating effects of ego-resilience and coping strategy, social support in the relationship between life stress and on adjustment in college life," Doctoral dissertation, Catholic University of Daegu, (2014)

[3] Jimenez, C., Navia-Osorio, P. M., and Diaz, C. V., "Stress and health in novice and experienced nursing students," Journal of Advanced Nursing, vol.66, no.2, pp.442-455, (2010)

[4] J. H. Lee, "Convergence study of life stress and health clinic user satisfaction in female students: Focused on the one women's university," Journal of the Korea Convergence Society, pp.89-96, (2016)

[5] Hwang, E. H., Kim, K. H., and Shin, S. J., "The effect of life stress, sleep quality, and depression on suicidal ideation among nursing students," Journal of the Korean Society for Wellness, vol.11, no.3, pp.3239-248, (2016)

[6] H. J. Park and J. W. Oh, "The relationships of the clinical practice stress and the major satisfaction with the nursing professionalism of nursing college students," Journal of Digital Convergence, vol.12, no.12, pp.417426, (2014) 
[7] Lee, D. Y., Park, J. K., and Choi, M. Y., "The relation between the stress of clinical practice and burnout among nursing students: The mediation effect of spiritual well-being," The Journal of Korean Academic Society of Nursing Education, vol.23, no.3, pp.300-308, (2017)

[8] Whang, S. J., "The relationship between clinical stress, self-efficacy, and self-esteem of nursing college students," The Journal of Korean Academic Society of Nursing Education, vol.12, no.2, pp.205-213, (2006)

[9] Y. J. Kim, Y. Y. Kim, and S. M. Lee, "The relationships among self-esteem, satisfaction with major, career identity, and university life adjustment of university students in the department of children's English education,” Journal of Digital Convergence, vol.13, no.9, pp.39-47, (2015)

[10] K. H. Kim and H. S. Ha, "A study of department satisfaction factors of undergraduate students," The Korean Journal of Counseling, vol.1, no.1, pp.7-20, (2000)

[11] Kyum K. C and Kyo H. K., "Development of the life stress scale for college students: A control theory approach,” Korean Journal of Psychology, vol.10, no.1, pp.137-158, (1991)

[12] Shin H. J. and Kim C. T., "Validation study of coping strategy indicator (CSI)," Korean Journal of Psychology, vol.14, no.4, pp.919-935, (2002) 
Stress and Coping to Nursing College Students

This page is empty by intention. 